\title{
Reducing $\mathrm{HCl}$ Release to the Environment by Eliminating Methyl Chloride at Reactors End of Run
}

\author{
Rahul Patil*, Kevin Rickert* \\ Specialty Chemicals (Agricultural Products), Texas, USA \\ Email address: \\ rahulrpatil@gmail.com (R. Patil), knr536@gmail.com (K. Rickert) \\ ${ }^{*}$ Corresponding author
}

\section{To cite this article:}

Rahul Patil, Kevin Rickert. Reducing HCl Release to the Environment by Eliminating Methyl Chloride at Reactors End of Run. American Journal of Chemical Engineering. Special Issue: Advances in Catalysis Science and Technologies for Biomass Conversion to Bioenergy and Biofuels. Vol. 8, No. 1, 2020, pp. 5-10. doi: 10.11648/j.ajche.20200801.12

Received: June 6, 2019; Accepted: February 10, 2020; Published: February 28, 2020

\begin{abstract}
Study of unreacted $\mathrm{MeCl}$ clearing from CSTR reactors at the end of run: It is a unique set up with CSTR reactors in cascade, used to produce salt-based product, esters and methanol from this unit operations. This study involves chemical reaction Engineering and process improvement experiments along with control logics to perform the steps to eliminating $\mathrm{MeCl}$ to the environment either in vapor or liquid form. $\mathrm{pH}$ and agitation speed are critical criterion to determine the presence of $\mathrm{MeCl}$ in the final drained liquid after the end of run. Process trends have been depicted in the study to verify the authenticity of the steps followed. Practical methods have been run through the lab analysis as well as studies done through the real unit operations environment. Reaction calculation was also part of methods used to conclude some portion of the study. Most literatures were referred through $\mathrm{MeCl}$ thermal and physical property data through published safety data sheets and pending patents on scrubbing methods of MeCl. Data was also collected through lab analysis on GC spectrometry with both gas and liquid methods, collected reading from unit operations at different ranges of pressure profile. This discussion would involve the use of water and caustic wash to react most of the $\mathrm{MeCl}$ out. The point in question is to minimize or eliminate of $\mathrm{HCl}$ emissions generated through unreacted $\mathrm{MeCl}$ when reactors are at the end of run and eventually getting washed off. Study concludes by giving quantity of $\mathrm{MeCl}$ (eventually $\mathrm{HCl}$ ) sent to flare or thermal oxidizer to eventually burn-out. Recommendations were made with respect to number of cycles of wash to minimize the inert levels, thermal efficiency improvement to crack down the $\mathrm{MeCl}$ down that will be burned as well as changes in handling the unit operations. Conclusions are based on flash calculations, chemical reaction between Caustic, Water and $\mathrm{MeCl}+$ heat through steam jackets with combinations of pressure and temperature changes. Results published with the successful run of the process that is being recommended through the study.
\end{abstract}

Keywords: Chlorine Emissions, Thermal Oxidizer for Organic Vents, Methyl Chloride Elimination, Caustic Scrubbing Method, Environment Health \& Safety Compliance

\section{Introduction}

Methyl chloride is the largest natural source of ozone-depleting chlorine compounds, and accounts for about 15 per cent of the present atmospheric chlorine content [1]. This contribution was likely to have been relatively greater in pre-industrial times [2]. Halogenated organic compounds play an important role in atmospheric chemistry as portrayed through atmospheric chemistry study with projecting the main source [3]. Environment compliances with regards to industrial releases are very stringent. One must pay close attention to the how much $\mathrm{MeCl}$ can be escaping through thermal oxidizer or through flare system with respect to the environment permit allotment. Concern is how to eliminate the $\mathrm{MeCl}$ that is saturated in the water when being released during the wash cycles during the reactors end of run or during MSS (maintenance start-up and shut-down) cases. It is considered hazardous material as per OSHA Communication Standard (29 CFR 1912.1200) [4]. When water saturated with $\mathrm{MeCl}$ is released to the closed sump running at slightly positive pressure, $\mathrm{MeCl}$ flashes out to release it to the low-pressure vent system to end up at thermal oxidizer. As this $\mathrm{MeCl}$ converts to $\mathrm{HCl}$ through a pyrolysis process when released through the thermal oxidizer with the destruction efficiency of 98\% [5].

Attempt has been made to successfully performing a 
chemical destruction of highly volatile material during the vessel shut-down process. This is lab-based experiment with trial performed at the large scale to gather the data for analysis to weigh the success of the approach. This method is mainly chosen to accommodate the volume of the chemicals that needs to be handled while controlling pressure and temperature at the same time.

$\mathrm{MeCl}$ is a toxic compound which is used in our process mainly through series of reactors with the liquid inventory controlled nominally@85-90\% level [6]. Other tests have also proven such as alcohol solvents and ratio of alcohol to water is below 1:3, the ability of solution to dissolve $\mathrm{MeCl}$ becomes unacceptably low [7]. Each reactor is pressure controlled by manipulating a volatile methyl chloride (raw material) when being fed into the vessel. The pressure set points are staggered, so there is a pressure differential for the level control loop to work with. Conversion is highest in the first reactor, with less and less as you move through the train. Some flashing of the methyl chloride must occur as one lets down the upstream reactor into the next reactor. The current method of stabilizing the level is to vent off methyl chloride to lower the pressure in the oscillating vessel(s). It has been noted that lowering the $\mathrm{MeCl}$ pressure is improving the "pulsation dampener" performance of the head space, which also smooths the $\mathrm{MeCl}$ feed rate to that reactors. Level control valves at the bottom of each reactor are taking almost all the frictional pressure drop. These are relatively short $(60 \mathrm{ft}), 3$ " diameter pipe carrying a maximum forward flow of 95-100 gpm.

\section{Experimental Setup: Lab and Field}

Experiments have been performed in the lab via. single reactor as shown in Figure 1, and then implemented to full scale reactors to verify the validity of the process. Methyl chloride breaks down to methanol, water and remaining methyl chloride as one common method of preparing chlorinated methane is to directly chlorinate methane, while another common method involves the hydrochlorination of methanol to produce methyl chloride, which is further chlorinated to provide the desired product(s). Though the direct chlorination of methane is economically advantageous, the hydrochlorination of methanol is more common [8]. Figure 1 shows the batch reactor with $\mathrm{pH}$ probes, controller and agitator with controller and pressure regulator is setup in the lab. The main reaction is with salt feed with $\mathrm{MeCl}$ to give product and $\mathrm{KCl}$, with other side reactions it produces salts and $\mathrm{MeOH}$. An overview reaction provided in reaction (1)

$$
\text { K-Na-salts }+\mathrm{MeCl}+\mathrm{H}_{2} \mathrm{O}+\mathrm{NaOH} \text {-----> Na-salts }+\mathrm{MeOH}+\text { by-product (Methyl Esters \& } \mathrm{HCl} \text { ) }
$$

Two major side reactions are hydrolysis of $\mathrm{MeCl}$ and esterification of Na-Salts [9]. Caustic is used to control the $\mathrm{pH}$ value while the $\mathrm{MeCl}$ is to control the reactor pressure.

This methylation process is run as batch methylation reaction while measuring $\mathrm{pH}$ through $\mathrm{pH}$ probe calibrated between 7 and 10 .

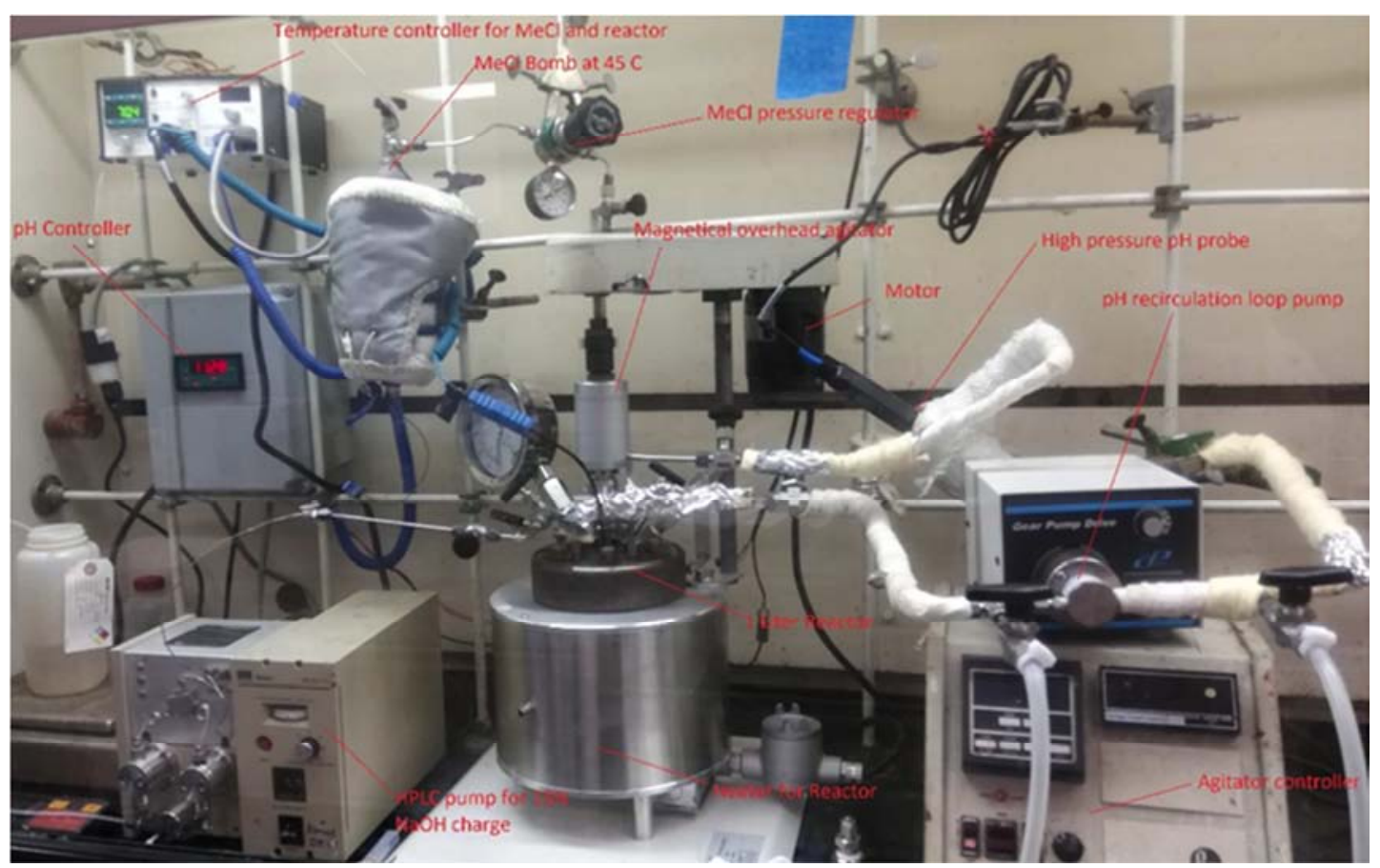

Figure 1. Lab setup of batch reactor.

The reactor in series (Figure 2) in the field have a radar level measurement along with pressure transmitter and agitator with seal oil system. Caustic is on flow control and $\mathrm{MeCl}$ is on pressure control. Steam flow to the vessel jacket is on temperature control of the vessel internal process.

As the field sketch from Figure 2 suggests the motor operated agitator on the top of the vessel denoted as letter M. Pressure, flow, temperature control releases data point for 
Setpoint (SP), Process Variable (PV), and Open\% (OP) of the control valves associated with each controller. Double block valves on $\mathrm{MeCl}$ feed line is to ensure there is no leak through when shut-off during the process.

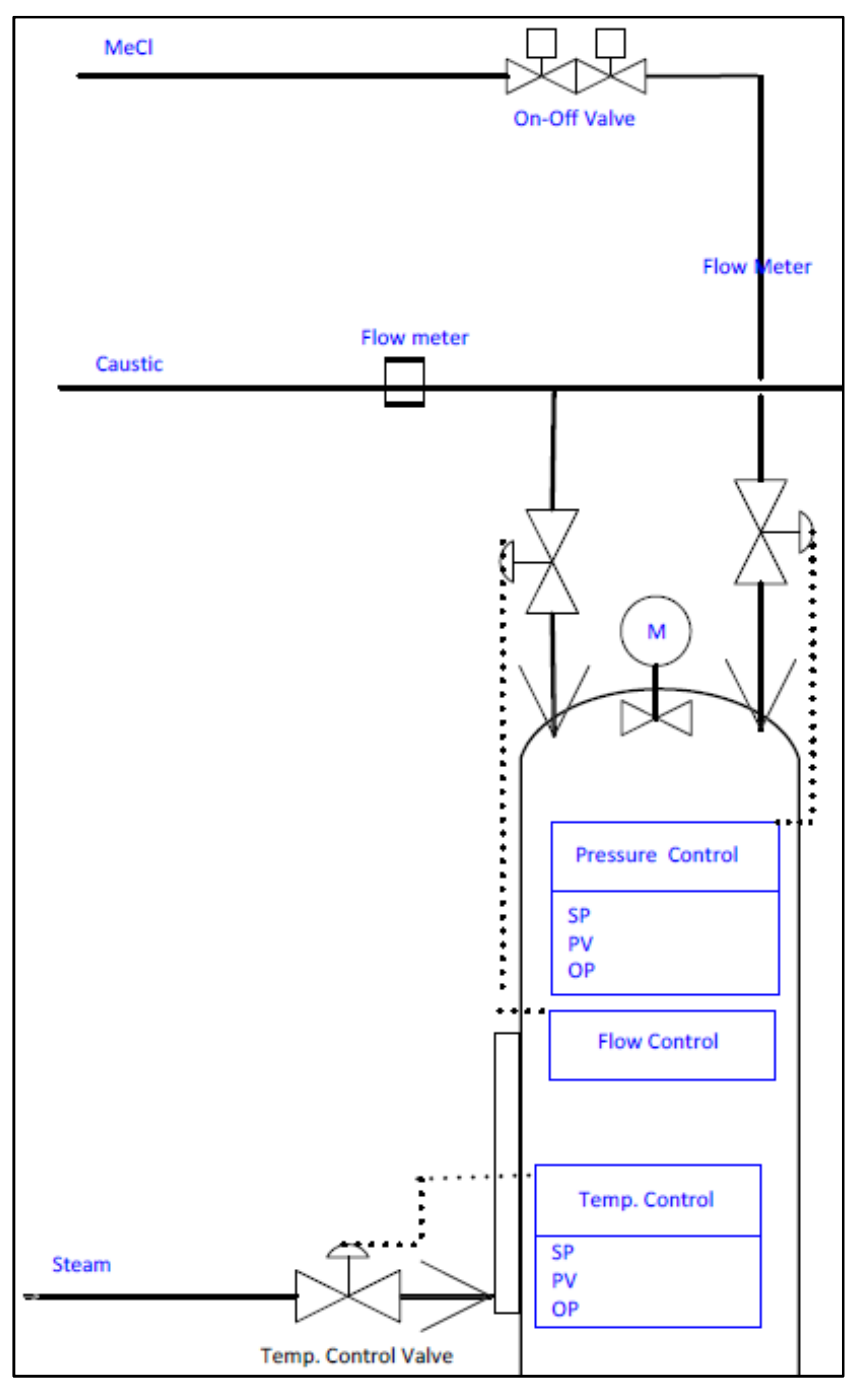

Figure 2. Field setup of the CSTR.

\section{Results and Discussion}

Details here discussed with field methods as basis of the experiment is to prove the implementation on a large scale is possible. As the process material is completely moved out of all the Methylators and the internal pressure is worked down to about flare pressure, Methylators are empty and $\mathrm{MeCl}$ will be in the vessel at this time. This step will be followed through per normal wash procedure. $\mathrm{MeCl}$ is blocked in to ensure no possible leak through. De-pressuring the vessel is slow enough to ensure on flaring issues occur. When at the last reactor running the process material out, $\mathrm{MeCl}$ feed line is purged using nitrogen towards the reactor this way the process fluid consumes most of $\mathrm{MeCl}$ trapped in the system.

There is successful catalytic combustor been presented in previous studies that could destroy $\mathrm{MeCl}$ efficiently [10, 11], but due to multiple sources of chlorinated compounds and with a different form present in the real industrial environment, it becomes difficult to predict the combustion result. Moreover, EPA test methods proven that there will be chlorinated compounds always present even with a Destruction Reduction Efficiency of $99.9 \%$ in the combustor.

Pressure in the vessel is brought down about 1 psig by venting it to the flare. Fill hot water from the bottom of vessel only in the first reactor to $>90 \%$ level to ensure minimum vapor space available for $\mathrm{MeCl}$. $60 \#$ steam is lined to the vessel jackets to maintain the temperature of about 150-160 F. As expected, the $\mathrm{pH}$ values are in the range of $\sim 2$ to 3 . Any pressure that will be raised during the water fill step has to be relieved to flare through nitrogen padded vessel downstream. Start agitator once the water level reaches $30 \%$. Once the reactor is @ $>90 \%$, pH of the vessel water sample is taken as a base line. Caustic is added to the vessel with feed rate of $\sim 0.3$ to 0.5 GPM for 30 mins. Caustic addition is repeated until $\mathrm{pH}$ target is reached to 11 . Once at 11, free caustic and methanol using ATM-1001 method to measure the composition in the sample. Target free caustic is $0.5-1 \mathrm{wt} \%$. Table 1 represents the $\mathrm{pH}$, caustic, and Methanol data gathered during the process. As methanol shows better burning/thermal efficiencies compared to methane if the activation energies were to be same $[12,13]$.

Table 1. Reactor Samples During Caustic Wash.

\begin{tabular}{lllll}
\hline Sample ID & Date and Time & Methanol (wt\%) & NaOH (wt\%) & pH \\
\hline $1^{\text {st }}$ Reactor & $09 / 03 / 2019,15: 30$ & 0.17 & 0.20 & 5.4 \\
$1^{\text {st }}$ Reactor & $09 / 03 / 2019,22: 30$ & 0.36 & 0.31 & 7.8 \\
$1^{\text {st }}$ Reactor & $09 / 03 / 2019,23: 00$ & Not tested & 0.38 & 9.4 \\
$1^{\text {st }}$ Reactor & $09 / 04 / 2019,01: 13$ & Not tested & 0.60 & 10.8 \\
Last Reactor & $09 / 04 / 2019,05: 00$ & 0.85 & 0.51 & 5.1 \\
Last Reactor & $09 / 04 / 2019,19: 30$ & 0.30 & 0.13 & 6.9 \\
Last Reactor & $09 / 04 / 2019,22: 40$ & Not tested & 0.33 & 8.1 \\
Last Reactor & $09 / 04 / 2019,23: 40$ & Not tested & 0.26 & 9.5 \\
Last Reactor & $09 / 05 / 2019,01: 30$ & 0.40 & 0.77 & 11.0 \\
\hline
\end{tabular}

Figure 3 shows the aspen trend of the above process that is followed in the first reactor. Legend sheet for figure $3, \mathrm{MeCl}$ is in blue, red is the water level in the reactor, orange is the agitator amphere readings, turquois is for caustic addition, pink is the fluid temperature in the vessel, finally green is the pressure. Figure 4 represents the aspen trend on last reactor before safely draining the water out the closed sump. 


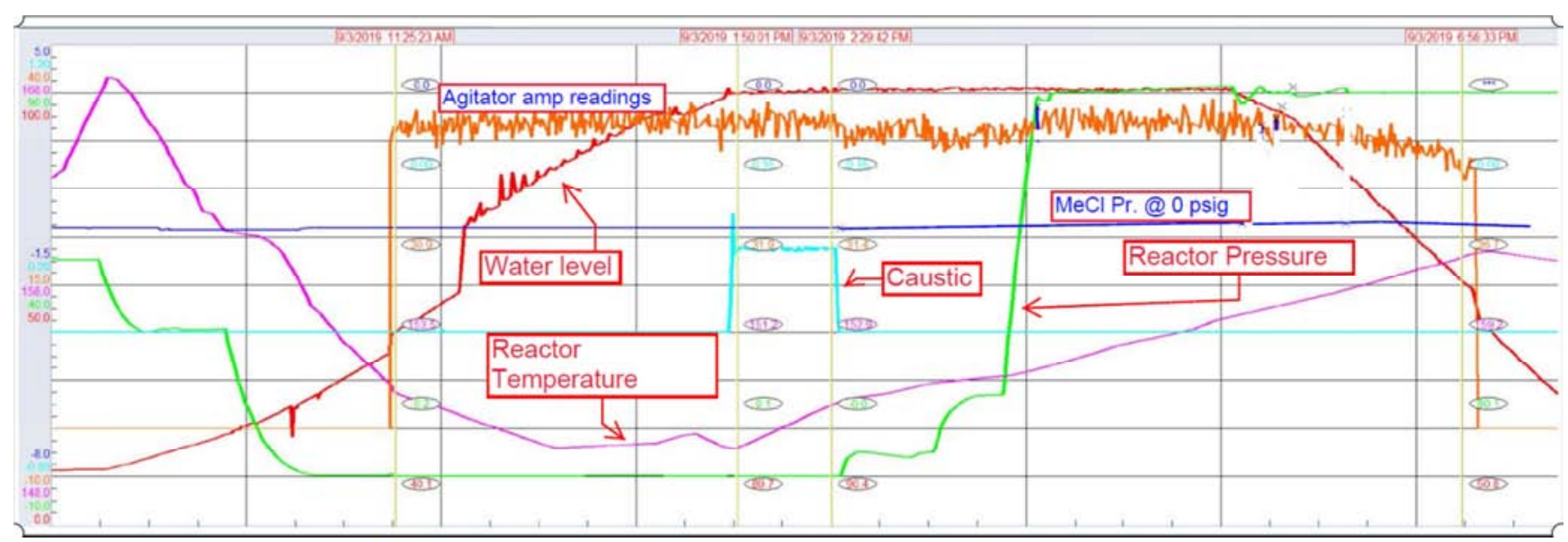

Figure 3. Aspen trend of first field reactor used for $\mathrm{MeCl}$ elimination process.

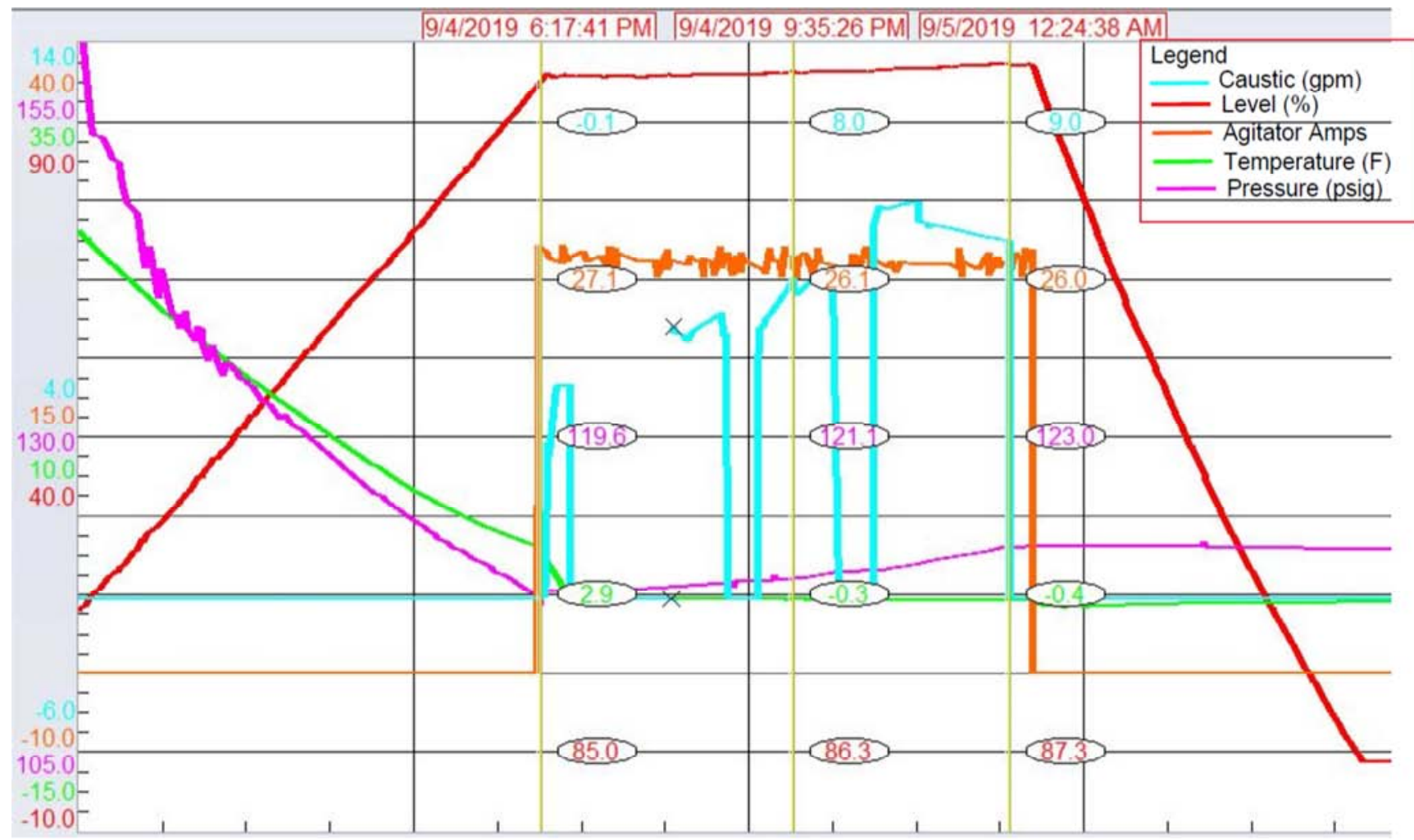

Figure 4. Aspen trend of final reactor used for MeCl elimination process before draining out to closed sump.

As the first vessel confirms almost all $\mathrm{MeCl}$ is converted to Methanol and salts, while $\mathrm{pH}$ and free caustic confirming $\mathrm{MeCl}$ is eliminated in the released water. As the other vessels in the series is sitting with $\mathrm{MeCl}$ in it, this water from the first vessel is transferred to next vessel in line. Nitrogen in the head space is used to gravity flow liquid to next vessel. These above steps were repeated for each vessel until $\mathrm{MeCl}$ from the last vessel is been eliminated. After the process is complete the nitrogen in each vessel can be released to the flare system, keeping the vessel ready for actual process.
Lab data is represented through similar steps as discussed in the field experiment with difference of no level reading due to known volume of the lab reactor, the relief of highpressure event is not considered due to the experiment is performed under the controlled vent hood system and the agitator is used with a variable frequency drive. Figure 5 shows the $\mathrm{MeCl}$ overall conversion chart. As discussed above $\mathrm{MeCl}$ breaks down to salts, methanol, and esters. Figure 6, methanol formation versa reaction time at different agitation speed is analyzed through lab experiment as well. 


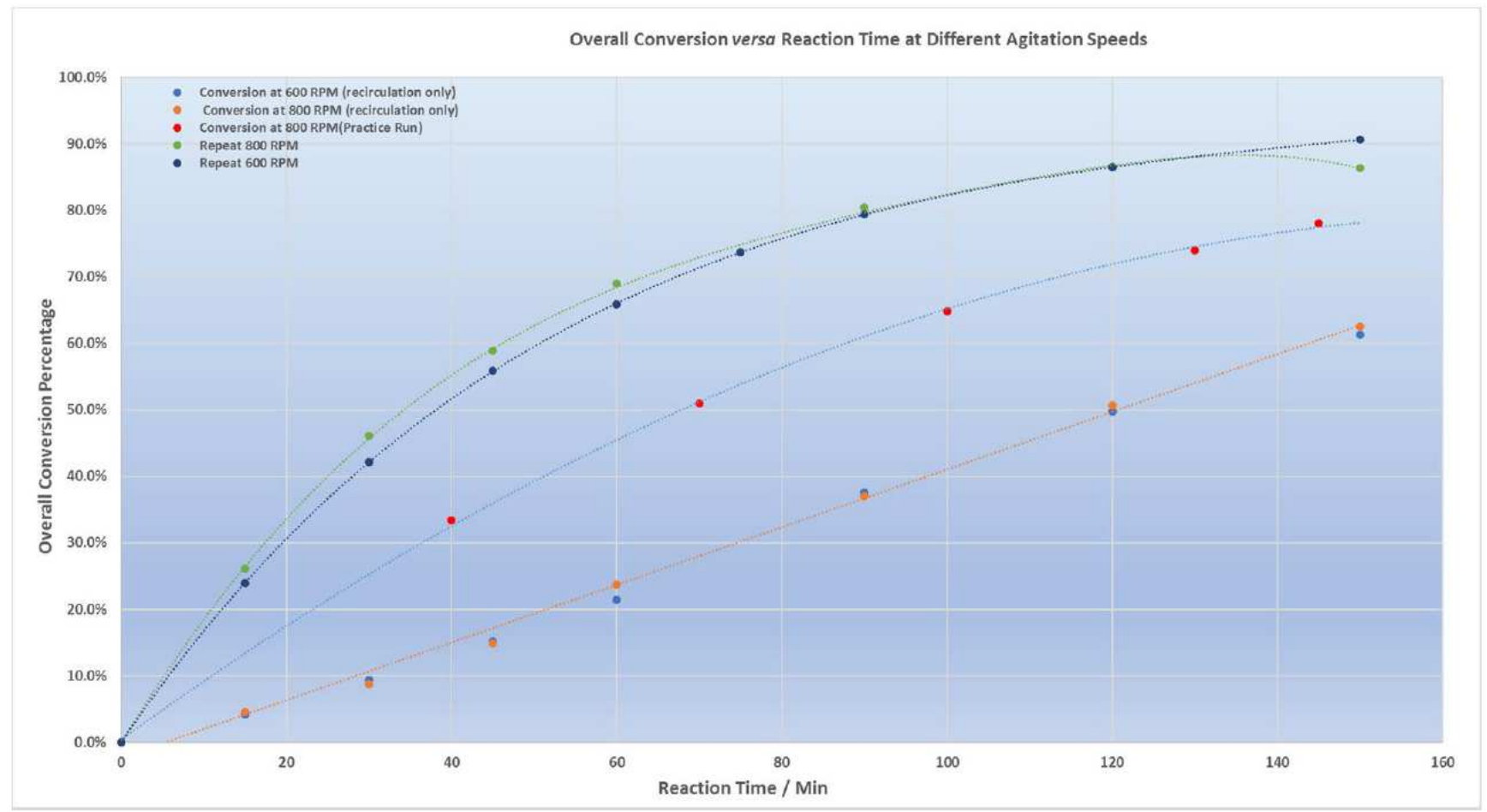

Figure 5. Overall conversion of $\mathrm{MeCl}$ vs. reaction time at different agitator speed.

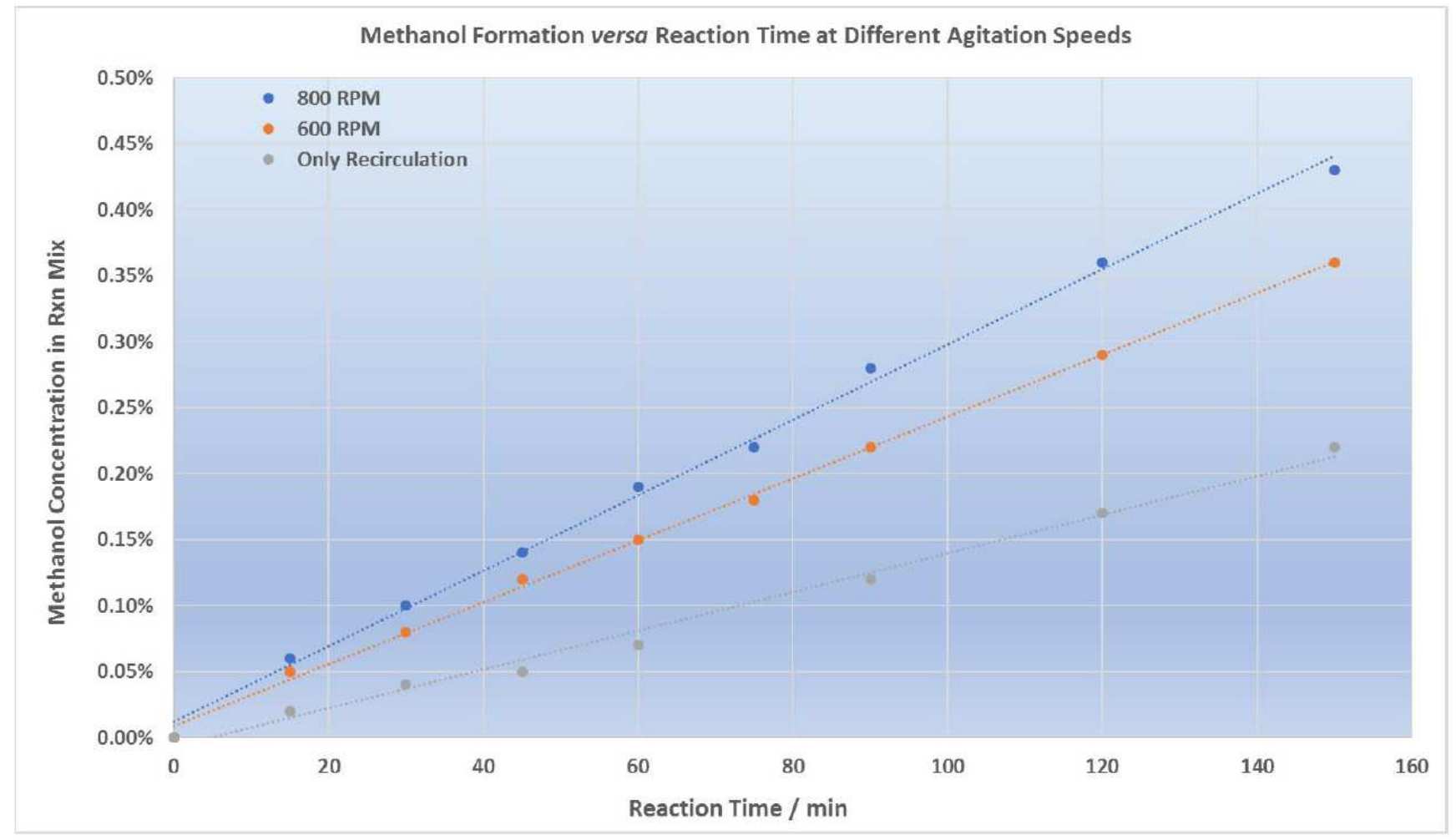

Figure 6. Methanol concentration in reaction mix vs. reaction time with different agitation speed.

The success of thermally oxidizing organics or hydrocarbons are presented in previous studies mostly using methane as the primary component $[14,15]$. 


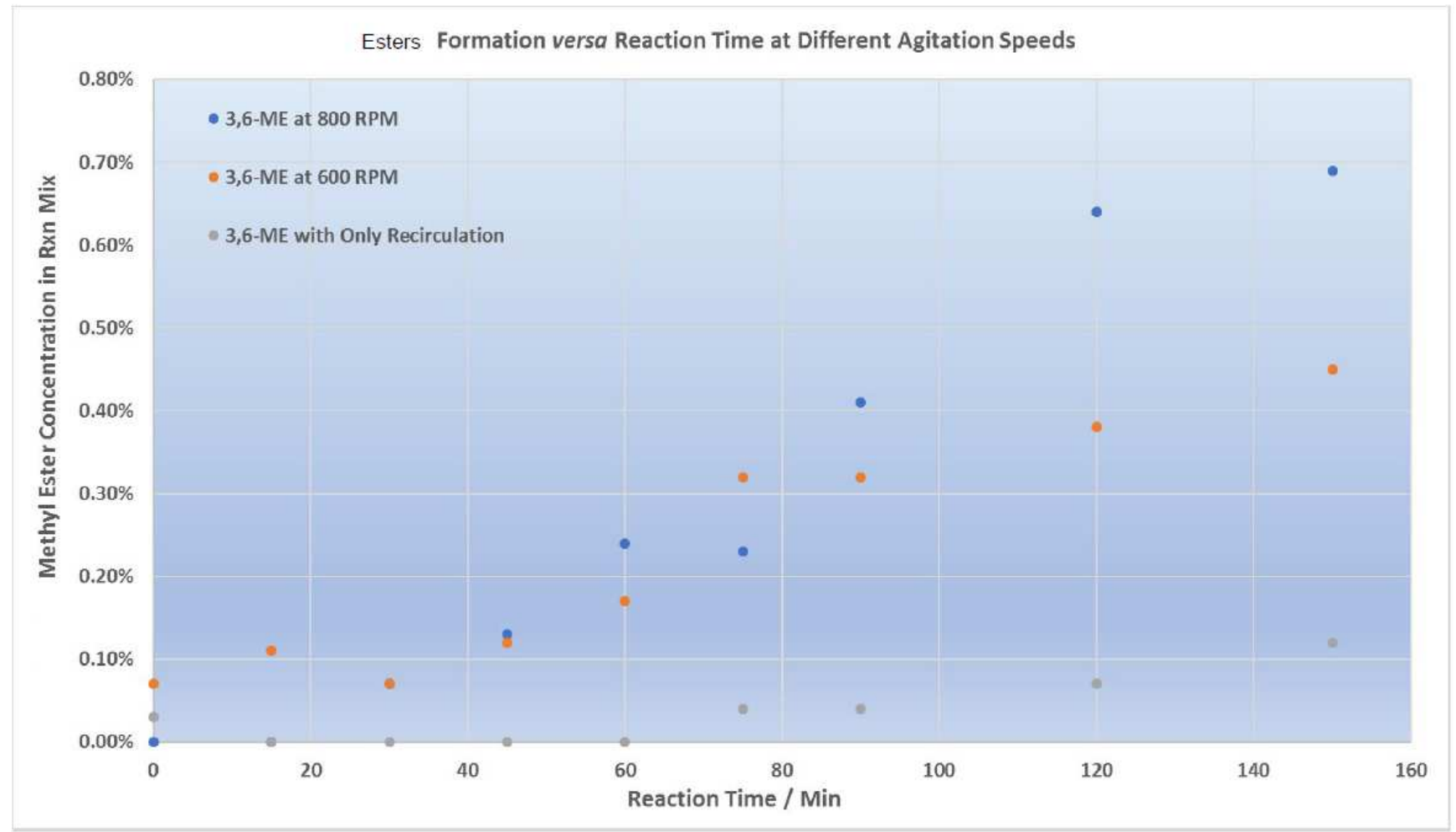

Figure 7. Esters concentration in reaction mix vs. reaction time with different agitation speed.

Very minimal esters are formed during the process of $\mathrm{MeCl}$, figure 7 represents the trend of reaction time versa ester concentration in $\mathrm{wt} \%$. These experiments were performed in addition to the above field process to verify if the agitator speed can enhance the reaction and reduce the overall time of reacting the $\mathrm{MeCl}$ out.

\section{References}

[1] Butler, J. H. Better budgets for methyl halides, Nature 403, 260-261 (2000).

[2] Butler, J. H. et al. A record of atmospheric halocarbons during the twentieth century from polar firn air. Nature 399, 749-755 (1999).

[3] Atmospheric Chemistry of Halogenated Organic Compounds, Timothy J. Wallington, Mads P. Sulbaek Andersen and Ole John Nielsen https://doi.org/10.1142/9789813147355_0005

[4] Occupational Safety \& Health Standard, regulation (standard 29 CFR), subpart title: Toxic and Hazardous Substances, part \# 1910, standard \# 1910-1200.

[5] Maia Weissman, Sydney W. Benson, Pyrolysis of methyl chloride, a pathway in the chlorine - catalyzed polymerization of methane, International Journal of Chemical Engineering (307-333) (1984).

[6] Safety Data Sheet, Methyl Chloride.

[7] United States Patent, Patent Number: 5,419,885, METHOD FOR THE DESTRUCTIVE SCRUBBING OF METHYL CHLORIDE. Henry Doran, Bray; Brian Keaveny.
[8] United States Patent, Patent No.: US 10, 329, 226 B2. Date of Patent: Jun. 25, 2019; PROCESS FOR THE PRODUCTION OF CHLORINATED METHANES.

[9] United States Patent, Patent Number: 1,688,726, Hydrolysis of methyl chloride, Ralph H. McKee.

[10] Stephen L. Hung and Lisa D. Pfefferle, Methyl chloride and methylene chloride incineration in a catalytically stabilized thermal combustor, Environmental Science \& Technology 198923 (9), 1085-1091, DOI: 10.1021/es00067a003.

[11] Hubert T. Henderson and George Richard Hill, A Kinetic Study of Methyl Chloride Combustion, The Journal of $\begin{array}{lllll}\text { Physical Chemistry } 1956 & 60 & \text { (7), } & 874-878 & \text { DOI: }\end{array}$ 10.1021/j150541a010.

[12] Wendell H. Wiser, George RichardHill, A kinetic comparison of the combustion of methyl alcohol and methane, Volume 5, Issue 1, 1955, Pages 553-558, https://doi.org/10.1016/S00820784(55)80073-2.

[13] Rex T. Skodje, Alison S. Tomlin, Stephen J. Klippenstein, Lawrence B. Harding, and Michael J. Davis, Theoretical Validation of Chemical Kinetic Mechanisms: Combustion of Methanol, The Journal of Physical Chemistry A 2010114 (32), 8286-8301, DOI: 10.1021/jp1047002.

[14] Ralph H. McKee and Stephen P. Burke, The Conversion of Methyl Chloride to Methanol-I, Industrial \& Engineering Chemistry 192315 (7), 682-688, DOI: 10.1021/ie50163a009.

[15] Philip A. Marrone, Russell P. Lachance, Joanna L. DiNaro, Brian D. Phenix, Jerry C. Meyer, Jefferson W. Tester, William A. Peters, and K. C. Swallow. Methylene Chloride Oxidation and Hydrolysis in Supercritical Water. 1995, 197-216. DOI: 10.1021/bk-1995-0608.ch013. 